\title{
The role of microparticles in pathomechanisms of diabetic retinopathy - analysis of intercellular communication mechanisms in endothelial aging. Case control study in patients with metabolic syndrome, diabetes type 1 and type 2
}

\author{
Ewa Stępień1, 2, Iwona Szuścik³ , Aleksandra Tokarz' , Francisco J. Enguita ${ }^{4}$, Bogdan Solnica', \\ Aleksander Żurakowski ${ }^{5}$, Maciej Małecki ${ }^{6}$ \\ ${ }^{1}$ Department of Clinical Biochemistry, Medical College, Jagiellonian University, Kraków, Poland \\ 2 Department of Medical Physics, M. Smoluchowski Institute of Physics, Jagiellonian University, Kraków, Poland \\ 3 Private Ophthalmology Practice OKO-LASER Outpatient Clinic, Kraków, Poland \\ ${ }^{4}$ Instituto de Medicina Molecular, Faculdade de Medicina, Universidade de Lisboa, Portugal \\ ${ }^{5}$ Department of Interventional Cardiology, American Heart of Poland SA, Chrzanów, Poland \\ ${ }^{6}$ Department of Metabolic Disease, Medical College, Jagiellonian University, Kraków, Poland
}

\begin{abstract}
The project is proposed to explain the role of specific circulating microparticles (MPs) as conveyors in trafficking bio-active molecules in type 1 (T1DM) and type 2 (T2DM) diabetic patients with risk of diabetic retinopathy (DR) and in patients with metabolic syndrome (MS). The possible role of miRNAs as modulators of these processes (in switching on/off mechanism on the molecular level) is proposed. An increased number of MPs with respect to glucose concentrations and levels of proangiogenic factors in vivo (patients' plasma) is expected. The relationship between age of patents and MP content (cell membrane glycoproteins, phosphatidylserine or miRNA profile) is possible. MPs will be obtained from T1DM $(n=30)$ T2DM $(n=30)$, MS $(n=30)$ and controls $(n=30)$. Retinopathy in diabetic patients will be assessed by imaging method. Biological profile of MPs will be assessed in vitro by means of flow cytometry, molecular biology methods and cell proliferation assays.
\end{abstract}

Keywords: microparticles, endothelium, diabetic retinopathy, miRNA, vascular ageing.

\section{General information}

The project "The role of microparticles in pathomechanisms of diabetic retinopathy - analysis of intercellular communication mechanisms in endothelial aging" was awarded by the Polish National Science Center (NCN) in the 7th edition of OPUS competition under grant number 2012/07/B/NZ5/02510. The contract between NCN and Jagiellonian University Medical College (JUMC) was signed on $26^{\text {th }}$ of June 2013 and the duration of the project is planned for 36 month, until $25^{\text {th }}$ of June 2016.
The clinical part of the projects is a prospective case-control study in a group of diabetic patients with a high risk of retinopathy. The project is interdisciplinary in nature and requires a close co-operation of specialists in clinical and laboratory medicine and basic science.

This project aims to combine recent progress in molecular and cell biology with the new approach for understanding the sequence of events on molecular and cellular levels leading to diabetic retinopathy (DR). The project adds a new piece of puzzle to understand- 
ing how hyperglycemic conditions affect retina, vascular (endothelial) and beta-cells to secretion of microparticles (MPs). It is assumed to characterize MPs released in this way (miRNA content), and compare this characteristic with in vivo conditions, with MPs obtained from metabolic syndrome, T1DM and T2DM patients.

\section{Management}

The Principal Investigator of this project is Associate Professor Ewa Stępień (PhD), a specialist in laboratory medicine (genetics) from Department of Medical Physics Jagiellonian University and Department of Clinical Biochemistry JUMC.

Co-investigators are: Professor Maciej Małecki (MD, $\mathrm{PhD}$ ) from Department of Metabolic Disease JUMC, Iwona Szuścik (MD, PhD) from Private Ophthalmology Practice OKO-LASER Outpatient Clinic in Kraków, Associate Professor Bogdan Solnica (MD, PhD) and Aleksandra Tokarz (MSc) from Department of Clinical Biochemistry JUMC and Aleksander Żurakowski from Department of Interventional Cardiology, American Heart of Poland SA, Chrzanów.

The International Partner is Assistant Professor Francisco J. Enguita (BPharm, PhD) from Instituto de Medicina Molecular, Faculdade de Medicina, Universidade de Lisboa, Portugal.

\section{Ethics}

Bioethical Committee at JUMC accepted all project's protocols and forms, including information for patients form and consent form for participation in the research study on $24^{\text {th }}$ October 2013 . The permission No. KBET/206/B/2013 is valid until $31^{\text {st }}$ of December 2016.

\section{Finance}

The project is mainly financed by a grant from NCN Life Science Panel in the $7^{\text {th }}$ OPUS call dedicated to "Human and animal noninfectious diseases mechanisms, diagnosis and treatment of diseases, poisonings and injuries". The total amount of grant funding is 697,100 PLN (about 169,000 Euro). Grant funds were earmarked to purchase reagents for molecular biology, biochemistry and flow cytometry methods, disposable laboratory equipment, laboratory instrumentation for the conducting of proposed research and data analysis. In addition, grant funds were designed to cover personnel costs of project participants and costs associated with the dissemination of research results, i.e., through publications in peer reviewed journals and presentations at professional scientific conferences.

\section{Research basic concept}

Microparticles (MP) are small extracellular vesicles between 100 and $500 \mathrm{~nm}$, released by the cells in a strictly regulated, cytoskeleton dependent process. In contrast, exosomes are smaller in diameter (between 40 and $100 \mathrm{~nm}$ ) and they are released during constitutive or facultative exocytosis [1]. MPs are produced during shedding process in response to some stressing factors like: hypoxia and injury or due to inflammation [2]. A number of cell types associated with the vascular system have been shown to release MPs: platelets, lymphocytes, macrophages, vascular endothelial cells and others (smooth muscle, retina, progenitor and cancer cells) $[3,4]$. MPs have been suggested to mediate local inflammation, thus they play a pivotal role in vascular diseases, such as atherosclerosis or DR $[5,6]$.

Endothelial dysfunction occurs when perturbed homeostatic endothelium disrupts vascular competence. These disruptions result in reduced vasodilatation, increased proinflammatory and prothrombotic property of the vascular network [7]. New insight in endothelial dysfunction, including the process of angiogenesis alteration is emerging from studies on vascular microvesicles such as endothelial MPs. It was previously documented that MPs derived from activated or apoptotic endothelial cells induce apoptosis in circulating angiogenic cells, and impair the atheroprotective and angiogenic function of the endothelium [8]. Impaired endothelial function is thought to be a denominator of pathogenesis of microvascular complications in T1DM and T2DM. It was documented that DR is associated with increased intima-media thickness (IMT) and endothelial dysfunction measured as concentrations of von Willebrand factor (VWF) and s-ICAM-1 [10] and elevated circulating ADMA [9].

MPs of endothelial, platelet, photoreceptor, and microglial origin were identified in vitreous samples and increased MPs of different origin in patients with DR may contribute to disease progression. The proinflammatory and pro-coagulation effects of MPs are mediated by specific lipid composition and/or by the transfer of pro-inflammatory factors from the cells of origin [11]. Moreover, endothelial microparticles (EMPs), released from apoptotic endothelial cells (ECs), influence cell repair of glucose damaged ECs by transferring microRNA [13]. 


\section{Research objectives}

The study primary objective is to characterize the profile of circulating MPs containing cell derived microRNA. This should allow to explain the mechanisms triggering undesirable events: thrombosis, apoptosis and degenerative vasculogenesis, which lead to DR.

One of the proposed mechanisms of DR is increased MP release from platelets and endothelial cells triggering TF in patients with complicated diabetes [14]. Apart from up-regulating effect on the expression of growth factors and chemokines, TF may directly promote ocular angiogenesis by the activation of MAPKand protein kinase C-dependent signalling (non-canonical pathways). Another mechanism proposes the transfer of secondary messenger molecules (receptors, lipids) mainly from immune cells (lymphocytes $T$ ), which regulates vascular function $[15,16]$. It was proposed, that failed angiogenesis in metabolic diseases is regu- lated by down-expression of vascular growth factors, via miRNA [17].

The secondary objective is the confirmation whether the exposure of endothelial cells to MPs generated in hyperglycemic conditions can induce calcium influx, cytoskeleton reorganization, VE-cadherin expression and catenin-beta translocation. It is important to distinguish the specific elements in this process, especially MPs content (miRNA) and their phenotype (origin) in the regulation of this machinery. This part of a study will be performed in vitro, in a cell culture model.

\section{Research plan}

The proposed project will be composed of two stages: Clinical stage - selection of individuals to 4 study groups T1DM ( $n=30)$ T2DM $(n=30)$, MS ( $n=30)$ and controls $(n=30)$ and analysis of classical risk factors and biomarkers; Basic stage - quantification

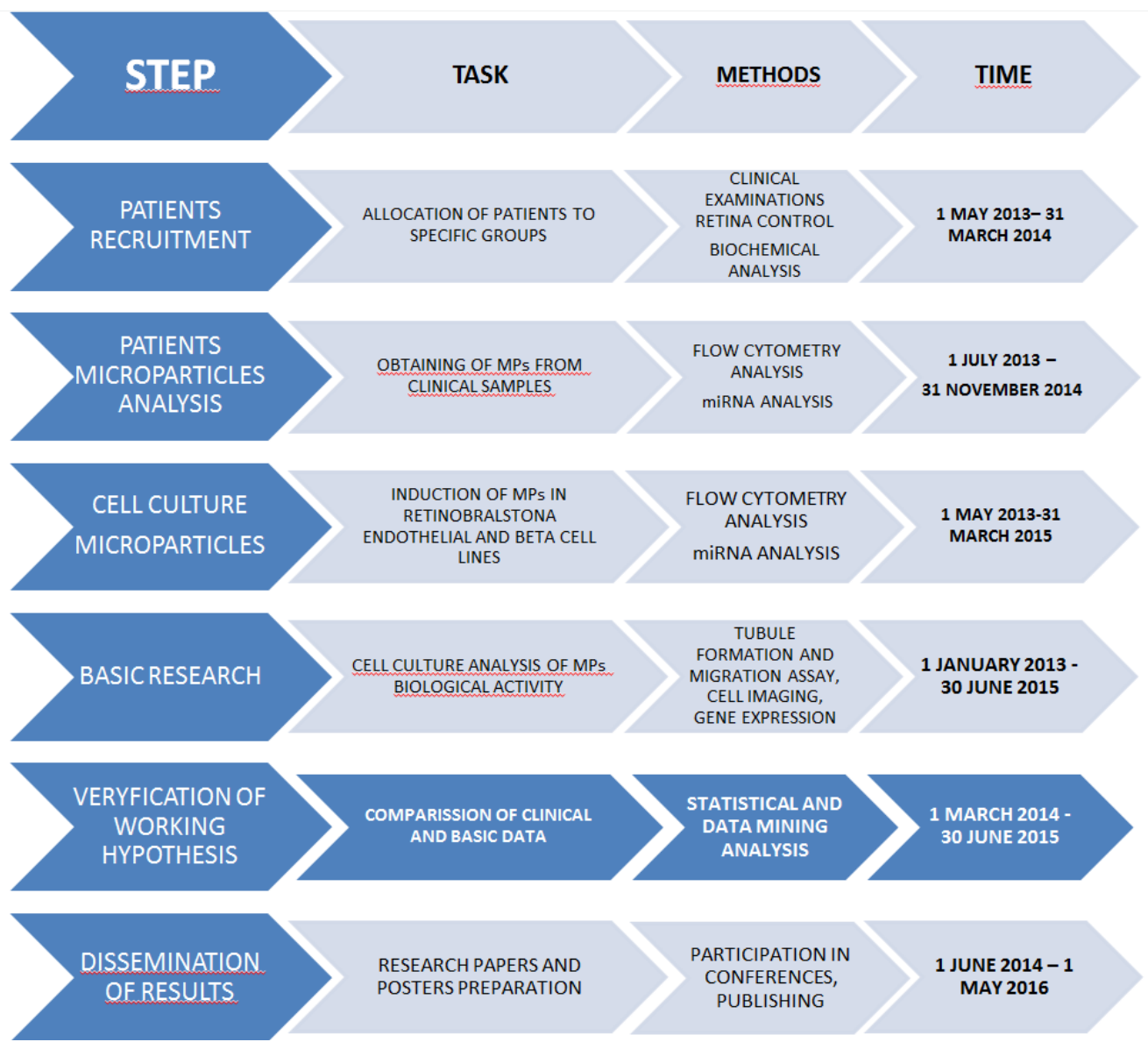

Figure 1. Work plan of the study "The role of microparticles in pathomechanisms of diabetic retinopathy - analysis of intercellular communication mechanisms in endothelial aging. Case control study in patients with metabolic syndrome, diabetes type 1 and type 2" 
of MPs, miRNA profiling, in vitro investigation. Time course of particular tasks is presented on Figure 1.

\section{Research methodology}

Study population

Up to 90 patients and 30 control subjects in age between 25-65 years will be enrolled into this study. All participants will be classified into 4 groups matching the inclusion criteria (Table 1). MS was will be defined according to the revised ATPIII criteria that require at least three of the following components: (1) abdominal obesity (waist circumference $\geqslant 102 \mathrm{~cm}$ for men or $\geqslant 88 \mathrm{~cm}$ for women), (2) triglycerides $\geqslant 150$ $\mathrm{mg} / \mathrm{dL}$, (3) HDL cholesterol $\leqslant 40 \mathrm{mg} / \mathrm{dL}$ for men or 50 $\mathrm{mg} / \mathrm{dL}$ for women or lipids lowering therapy, (4) systolic/diastolic blood pressure $\geqslant 130 / 85 \mathrm{mmHg}$ or receiving drug treatment, and (5) fasting plasma glucose $\geqslant$ $100 \mathrm{mg} / \mathrm{dL}[18]$.

\section{Assessment of clinical outcomes}

Length of time from entry to the study to when the clinical event will occur is planned no less than 2 years. Clinical outcomes will be assessed in primary and secondary end-points (Table 2).

\section{Sample collection}

All blood samples will be drawn at the same time of the day (between 08:00 and 10:00 am) with venipuncture with $>21$-gauge needle in the antecubital vein following the application of a tourniquet. The first 2-3 $\mathrm{ml}$ of blood will not be included for MP analysis (used for additional analysis). Citrate (for MPs and miRNAs) or EDTA (hematology, HbA1C, biomarkers) anticoagulation will be used. For biochemistry, serum samples will be collected. The blood samples will be separated to obtain Platelet Poor Plasma (PPP) or serum and frozen at $-80^{\circ} \mathrm{C}$ until analysis for miRNAs and selected biomarkers. Additionally, urine samples will be collected.

Table 1. Eligibility and inclusion criteria for patients enrolled to the project "The role of microparticles in pathomechanisms of diabetic retinopathy analysis of intercellular communication mechanisms in endothelial aging. Case control study in patients with metabolic syndrome, diabetes type 1 and type 2"

\begin{tabular}{|c|c|c|c|}
\hline $\begin{array}{l}\text { Type } 1 \text { Diabetes Mellitus (T1DM) } \\
\qquad \mathrm{n}=30\end{array}$ & $\begin{array}{l}\text { Type } 2 \text { Diabetes Mellitus (T2DM) } \\
\qquad \mathrm{n}=30\end{array}$ & $\begin{array}{l}\text { Metabolic Syndrome (MS) } \\
\qquad \mathrm{n}=30\end{array}$ & $\begin{array}{l}\text { Control group (CG) } \\
\quad \mathrm{n}=30\end{array}$ \\
\hline \multicolumn{4}{|c|}{ Inclusion criteria } \\
\hline \multicolumn{4}{|c|}{ Male and female subjects in age between $25-65$ years } \\
\hline \multicolumn{4}{|c|}{ Subjects who will give their informed consent to participate in the study, both in the enrolment and later follow-up. } \\
\hline Diabetes type 1 & Diabetes type 2 & $\begin{array}{l}\text { Metabolic syndrome according to } \\
\text { revised ATPIII criteria [18] }\end{array}$ & apparently healthy \\
\hline $\begin{array}{l}\text { BMl from } 18.5 \text { to } 24.9 / \mathrm{m}^{2} \\
\text { BMl from } 25.0 \text { to } 40.0 / \mathrm{m}^{2}\end{array}$ & $\begin{array}{l}\text { BMl from } 18.5 \text { to } 24.9 / \mathrm{m}^{2} \\
\text { BMl from } 25.0 \text { to } 40.0 / \mathrm{m}^{2}\end{array}$ & BMI from 30 to $40.0 \mathrm{~kg} / \mathrm{m}^{2}$ & BMI from 18.5 to $24.9 \mathrm{~kg} / \mathrm{m}^{2}$ \\
\hline $\begin{array}{l}\text { Diabetic Retinopathy (DR) assessed } \\
\text { by the colorful photographic } \\
\text { documentation of two } \\
45^{\circ} \text { retinal fields }\end{array}$ & $\begin{array}{c}\text { Diabetic Retinopathy (DR) assessed } \\
\text { by the colorful photographic } \\
\text { documentation of two } \\
45^{\circ} \text { retinal fields }\end{array}$ & - & - \\
\hline $\begin{array}{l}\text { Insulin resistance is not an } \\
\text { exclusion criterion }\end{array}$ & $\begin{array}{l}\text { Insulin resistance is not an } \\
\text { exclusion criterion }\end{array}$ & Insulin resistance & - \\
\hline \multicolumn{4}{|c|}{ Exclusion criteria } \\
\hline \multicolumn{4}{|c|}{$\begin{array}{l}\text { Acute Coronary Syndrome (ACS), acute Ischemic Stroke (IS) or critical limb ischemia will be excluded from this study. } \\
\text { A previous cardiovascular event (MI or IS) has to be at least } 6 \text { months prior to the study enrollment. }\end{array}$} \\
\hline \multicolumn{4}{|c|}{$\begin{array}{l}\text { History of cancer, renal and liver failure, and past or present systemic inflammation (hs-CRP > } 10 \text { mg/l), } \\
\text { such as active chronic arthritis or phospholipid syndrome. }\end{array}$} \\
\hline \multicolumn{4}{|c|}{ Known or suspected bacterial or viral infection } \\
\hline \multicolumn{4}{|c|}{ Treatments with steroidal and non-steroidal anti-inflammatory drugs, bariatric surgery } \\
\hline \multicolumn{4}{|c|}{ Pregnancy or Hormone Replacement Therapy (HRT) } \\
\hline Morbid obesity $>40.00 \mathrm{~kg} / \mathrm{m}^{2}$ & Morbid obesity $>40.00 \mathrm{~kg} / \mathrm{m}^{2}$ & Morbid obesity $>40.00 \mathrm{~kg} / \mathrm{m}^{2}$ & - \\
\hline- & - & - & Statin treatment \\
\hline
\end{tabular}

Table 2. Clinical outcomes of the project

\begin{tabular}{ll}
\hline Primary end-points & $\begin{array}{l}\text { An anatomic feature that is measured at the end of a study to assess the progression of DR: measure the area of choroidal } \\
\text { neovascularization, submacular leakage and hemorrhage }\end{array}$ \\
\hline Secondary end-points & Statistically and clinically relevant differences in visual function at more than one time point \\
\hline
\end{tabular}




\section{Laboratory analysis}

Standard blood tests including biochemistry (glucose, lipids, creatinine) will be performed. For biomarkers, ELISA and molecular biology methods are planned. MP enumeration and phenotype analysis will be performed by flow cytometry. Genetic analysis of miRNA profile and gene expression will be done by means of quantitative PCR methods or next generation (NG) sequencing. Cell culture methods will be used for assessment of MP induced endothelial proliferation and angiogenesis.

\section{Statistical analysis and methodology}

The hazard ratio for data summary and the risk assessment will be performed. The linear regression models will be used for the continuous variable analysis, like biomarkers and MPs enumeration. MicroRNA will be correlated with biomarkers levels and the MPs number using multiple regression models. The Cox proportional hazard regression model will be used for DR parameters with respect to MPs and miRNA covariates. Additionally data mining analysis will be performed to reveal any data relationships.

\section{Expected results}

The clinical part of this study will be directed to develop new methods and systems for diagnostics and treatment of endothelial dysfunction related to pathological endothelial proliferation/neovascularization, senescence and other hyperglycemia related defects that cause deficiencies of ocular system:

- development and application of universal diagnostics protocols,

- discovery of new biomarkers,

- manufacturing of new diagnostic tests,

- targeting of the disease (DR).

The further basic research phase of this study may have an important role in the promoting the new experiments on circulating MPs and miRNAs and may have a high impact on the future technologies which apply new biomarkers in prophylaxis, treatment and prognosis of DR. In this stage we expect:

- to verify the hypothesis about the mechanisms involved in the processes related to DR on the celIular level: cell-to-cell communication via MPs as transferring vesicles of regulatory molecules including miRNAs and proangiogenic proteins,

- to bring a new insight into the relation between MP exposure, endothelial cell cytoskeleton reorganization and activation of cell signaling,

- to explain the role of MPs in neovascularization on the molecular level.

\section{Acknowledgements}

\section{Conflict of interest statement}

The authors declare that there is no conflict of interest in the authorship or publication of contribution.

\section{Funding sources}

The project is mainly financed by a grant from NCN Life Science Panel in the 7th OPUS call dedicated to "Human and animal noninfectious diseases mechanisms, diagnosis and treatment of diseases, poisonings and injuries". The total amount of grant funding is 697,100 PLN (about 169,000 Euro).

\section{References}

1. Kim DK, Lee J, Kim SR, Choi DS, Yoon YJ, Kim JH, et al. EVpedia: A Community Web Portal for Extracellular Vesicles Research. Bioinformatics. 2014 Nov 10. DOI: 10.1093/bioinformatics/btu741.

2. Stępień E, Targosz-Korecka M. Microparticles in endothelial function. Post Biochem. 2013;59(4):395-404.

3. Orozco AF, Lewis DE. Flow cytometric analysis of circulating microparticles in plasma. Cytometry A. 2010 Jun;77(6):502-14. DOI: 10.1002/cyto.a.20886.

4. Stępień E, Kabłak-Ziembicka A, Czyż J, Przewłocki T, Małecki M. Microparticles, not only markers but also a therapeutic target in the early stage of diabetic retinopathy and vascular aging. Expert Opin Ther Targets. 2012 Jul;16(7):677-688.

5. Nomura S. Dynamic role of microparticles in type 2 diabetes mellitus. Curr Diabetes Rev. 2009 Nov;5(4): 245-251.

6. Konkolewska M, Kurc S, Stepień E. A thousand words about microparticles in cardiology. Journal of Medical Science. 2014;3(83):189-193.

7. Endemann DH, Schiffrin EL. Endothelial dysfunction. Journal of the American Society of Nephrology: JASN. 2004 Aug;15(8):1983-1992.

8. Mezentsev A, Merks RM, O'Riordan E, Chen J, Mendelev $\mathrm{N}$, Goligorsky MS, et al. Endothelial microparticles affect angiogenesis in vitro: role of oxidative stress. Am J Physiol Heart Circ Physiol. 2005 Sep;289(3):H1106-H1114.

9. Malecki MT, Undas A, Cyganek K, Mirkiewicz-Sieradzka B, Wolkow $\mathrm{P}$, Osmenda $\mathrm{G}$, et al. Plasma asymmetric dimethylarginine (ADMA) is associated with retinopathy in type 2 diabetes. Diabetes Care. 2007 Nov;30(11):2899-2901.

10. Małecki MT, Osmenda G, Walus-Miarka M, Skupień J, Cyganek K, Mirkiewicz-Sieradzka B, et al. Retinopathy in type 2 diabetes mellitus is associated with increased intima-media thickness and endothelial dysfunction. Eur J Clin Invest. 2008 Dec;38(12):925-930.

11. Morel O, Jesel L, Freyssinet JM Toti F. Cellular mechanisms underlying the formation of circulating microparticles. Arterioscler Thromb Vasc Biol. 2011 Jan;31(1): $15-26$.

12. Ren J, Zhang J, Xu N, Han G, Geng Q, Song J, et al. Signature of circulating microRNAs as potential biomarkers in vulnerable coronary artery disease. PLoS One. 2013 Dec 5;8(12):e80738.

13. Jansen F, Yang $X$, Hoelscher $M$, Cattelan A, Schmitz T, Proebsting $S$, et al. Endothelial microparticle-mediated 
transfer of MicroRNA-126 promotes vascular endothelial cell repair via SPRED1 and is abrogated in glucose-damaged endothelial microparticles. Circulation. 2013 Oct 29;128(18):2026-2038.

14. Hjortoe GM, Petersen LC, Albrektsen T, Sorensen BB, Norby PL, Mandal SK, et al. Tissue factor-factor VIla-specific up-regulation of IL-8 expression in MDA-MB-231 cells is mediated by PAR-2 and results in increased cell migration. Blood. 2004 Apr 15;103(8):3029-3037.

15. Kim HK, Song KS, Chung JH, Lee KR, Lee SN, et al. Platelet microparticles induce angiogenesis in vitro. $\mathrm{Br} J$ Haematol. 2004 Feb;124(3):376-384.

16. Rautou PE, Vion AC, Amabile N, Chironi G, Simon A, Tedgui $A$, et al. Microparticles, vascular function, and atherothrombosis. Circ Res. 2011 Aug 19;109(5):593-606.

17. McArthur K, Feng B, Wu Y, Chen S, Chakrabarti S. MicroRNA-200b regulates vascular endothelial growth factor-mediated alterations in diabetic retinopathy. Diabetes. 2011 Apr;60(4): 1314-1323.
18. Alberti KG, Zimmet P, Shaw J, IDF Epidemiology Task Force Consensus Group. The metabolic syndrome - a new worldwide definition. Lancet. 2005 Sep 24-30;366(9491):1059-1062.

Acceptance for editing: 2014-12-10 Acceptance for publication: 2014-12-31

\section{Correspondence address:} Ewa Stępień Department of Medical Physics M. Smoluchowski Institute of Physics Jagiellonian University 11 Łojasiewicza Street, 30-387 Kraków, Poland phone: +48 126644762 fax: +48126647086 email: e.stepien@uj.edu.pl 